\title{
CD20-Positive Peripheral T-Cell Lymphoma: Report of a Case after Nodular Sclerosis Hodgkin's Disease and Review of the Literature
}

\author{
Renee L. Mohrmann, M.D., Daniel A. Arber, M.D. \\ Division of Pathology, City of Hope National Medical Center, Duarte, California
}

\begin{abstract}
We present a case of peripheral T-cell lymphoma co-expressing CD3 and CD20, as well as demonstrating $\mathrm{T}$-cell receptor gene rearrangement, in a patient who had been diagnosed with nodular sclerosis Hodgkin's disease 5 years previously. Although 15 cases of CD20-positive T-cell neoplasms have been previously reported in the literature, this is the first report of CD20-positive T-cell lymphoma occurring subsequent to treatment of Hodgkin's disease. The current case affords an opportunity to review the rarely reported expression of CD20 in $T$-cell neoplasms as well as the relationship between Hodgkin's disease and subsequently occurring nonHodgkin's lymphomas. In addition, the identification of this case supports the suggestion that the use of CD20 antibodies alone in paraffin sections may lead to an incorrect determination of cell lineage in some cases.
\end{abstract}

KEY WORDS: CD20; flow cytometry; Hodgkin's disease; immunohistochemistry; secondary lymphoma; T-cell lymphoma

Mod Pathol 2000;13(11):1244-1252

In recent years, there have been several reports in the literature describing benign and malignant T-cell proliferations expressing the normally B-cellassociated antigen, CD20 (1-9). The neoplastic lesions have encompassed a variety of acute and chronic T-cell leukemias and lymphomas. Little is known about the significance of CD20 expression in these neoplasms, other than that its identification may cause confusion with a B cell process. The accompanying case report represents an effort to further characterize these unusual lesions.

Copyright () 2000 by The United States and Canadian Academy of Pathology, Inc.

VOL. 13, NO. 11, P. 1244, 2000 Printed in the U.S.A.

Date of acceptance: June 9, 2000.

Address reprint requests to: Renee L. Mohrmann, M.D., Division of Pathology, City of Hope National Medical Center, 1500 East Duarte Road, Duarte, CA 91010-3000 USA; fax: 626-301-8145; e-mail: mohrmann@coh.org.

\section{CASE REPORT}

A 47-year-old man presented in 1993 with a brief history of right axillary lymph node enlargement and mild fatigue. Biopsy showed nodular sclerosis Hodgkin's disease. He was treated with six courses of mechlorethamine, vincristine, procarbazine, prednisone/doxorubicin, bleomycin, vinblastine chemotherapy over a period of 6 months. Clinical remission was achieved for 5 years. In early 1998, the patient noticed enlargement of lymph nodes in the posterior cervical region, which were followed clinically for several months. Weight loss of $15 \mathrm{lbs}$., fatigue, and flu-like symptoms ensued. The lymph nodes became firmer to palpation and were biopsied, showing peripheral T-cell lymphoma, diffuse large-cell type. The patient then received six courses of methotrexate-bleomycin, doxorubicin, cyclophosphamide, vincristine, and prednisone chemotherapy over 18 weeks and was in remission at 7 months after diagnosis.

The patient's history is significant for a 15 packyear history of cigarette smoking. He had the usual child illnesses, including a "touch of pneumonia" as an infant; however, there was no history of infectious mononucleosis. No allergies were present. No toxic environmental or industrial exposures were elicited. The family history is significant for a sister having diabetes mellitus and gastric carcinoma.

\section{MATERIALS AND METHODS}

Both lymph node biopsies were reviewed in consultation in the Division of Pathology at the City of Hope National Medical Center (Duarte, California, USA).

Immunohistochemical studies were performed on paraffin sections using heat-induced epitope retrieval (10) by steaming for $20 \mathrm{~min}$, followed by the avidin-biotin complex method, as described previously (11), on an automated immunostainer (Techmate 1000, Ventana, Tucson, AZ, USA). Tissue from the initial and subsequent biopsies were evaluated 
with the following antibodies: EBV-LMP-1 (Dako, Carpinteria, CA, USA), CD2 (Novocastra, Newcastle upon Tyne, UK), CD3 (Dako), CD4 (Novocastra), CD5 (Novocastra), CD8 (Dako), CD15 (BectonDickinson, Mountain View, CA, USA), CD20 (Dako), CD30 (Dako), CD43 (Becton-Dickinson), CD45RA (Dako), CD45RB (Ventana), CD45RO (Zymed, South San Francisco, CA, USA), CD56 (Zymed), CD79a (Dako), EMA (Dako), perforin (Endogen, Woburn, MA, USA), granzyme B (Monosan, Sanbio, Uden, The Netherlands), and TIA-1 (Immunotech, Marseille, France).

Immunophenotyping studies were also performed using three- and two-color flow cytometry on cells in suspension prepared from the 1998 lesion, using a Becton-Dickinson FACScan instrument. After mononuclear cell enrichment by centrifugation over Histopaque-1077 (Sigma, St. Louis, MO), the cells were studied for surface CD45 antigen expression and right-angle light scatter, as described by Borowitz et al. (12), as well as for forward scatter and right-angle scatter. Isotype controls were performed to determine positive and negative cut-off values. The antigens detected and antibodies used were CD45/HLE-1, CD2/ Leu-5b, CD4/Leu-3a and Leu-3b, CD5/Leu-1, CD7/ Leu-9, CD8/Leu-2a, CD10/CALLA, CD14/Leu-M3, CD19/Leu-12， CD20/Leu-16， CD22(G2b)/Leu-14, CD23/Leu-20 (all from Becton-Dickinson), FMC-7 (Immunotech, Marseilles, France), IgG, IgM, IgD, IgA, Ig- $\kappa$, and Ig- $\lambda$ (all from Biosource, Camarillo, CA, USA). For all the above markers, the gated cells were considered positive if $20 \%$ or more expressed an antigen.

Epstein-Barr virus (EBV) RNA in situ hybridization studies were performed on paraffin sections using a 30-base oligonucleotide complementary to a portion of the EBER-1 gene as described previously (13). The polymerase chain reaction (PCR) was used to identify immunoglobulin heavy-chain variable-diversity-joining region gene rearrangements using primers complementary to the second and third framework region (FR2 and FR3) as described previously $(14,15)$. Rearrangements of $\mathrm{T}$ cell receptor- $\gamma$ (TCR- $\gamma$ ) variable genes 1 to 11 were also studied using PCR as described previously (16). The amplifiability of the DNA was confirmed by PCR-amplification of $\beta$-globin. Integrity of nucleotides for in situ hybridization was confirmed by use of a poly-d(T) probe.

Southern blot analysis was performed on DNA extracted from frozen 1998 lymph node tissue after digestion with restriction enzymes EcoRI, HindIII, and BamHI using a genomic probe specific for the constant region of the TCR $\beta$ chain gene. The blot was then stripped and probed with a genomic probe specific for the joining region of the TCR $\beta$ chain gene.

\section{RESULTS}

Hematoxylin and eosin-stained sections of the 1993 lymph node biopsy showed several enlarged reactive follicles with an expanded interfollicular region. The sinuses appeared patent. Scattered large, atypical mononuclear cells with vesicular chromatin and a prominent single nucleolus (sometimes approaching the size of a small lymphocyte), as well as mummified cells and rare, classic, binucleated Reed-Sternberg cells, were seen in and around sinuses and in parafollicular areas (Figure 1). These large cells had the following immunophenotype: CD15 weakly positive, CD30 positive, CD20 positive, CD79a weakly positive, CD45RB negative, EBV-LMP-1 negative, perforin weakly positive, granzyme B negative, TIA-1 negative. The expanded interfollicular areas contained small to medium-sized lymphocytes having slightly irregular nuclei, finely granular to vesicular chromatin, and inconspicuous to medium-sized nucleoli. These cells had moderate amounts of pale, slightly amphophilic, and agranular cytoplasm. Mitotic activity seemed moderately brisk and occasional atypical mitotic figures (sunburst and ring forms) were seen. The subpopulation of these lymphocytes adjacent to the larger Hodgkin's cells described above had the after immunophenotype: CD3 positive, CD30 weakly positive, CD8 negative, CD4 positive, CD20 negative, EBV-LMP-1 negative. There were rare necrotic foci with karyorrhectic nuclei and scattered neutrophils. The large atypical (Hodgkin's) cells were often seen in association with these necrotic foci. All cell types were EBVnegative by in situ hybridization using the EBER-1 RNA probe.

Sections of the 1998 lymph node biopsy (Figure 2a) showed loss of reactive follicles and effacement of normal nodal architecture. Sinuses were obliterated and the capsule was fibrotic. Sheets of medium to large neoplastic lymphocytes with moderate to

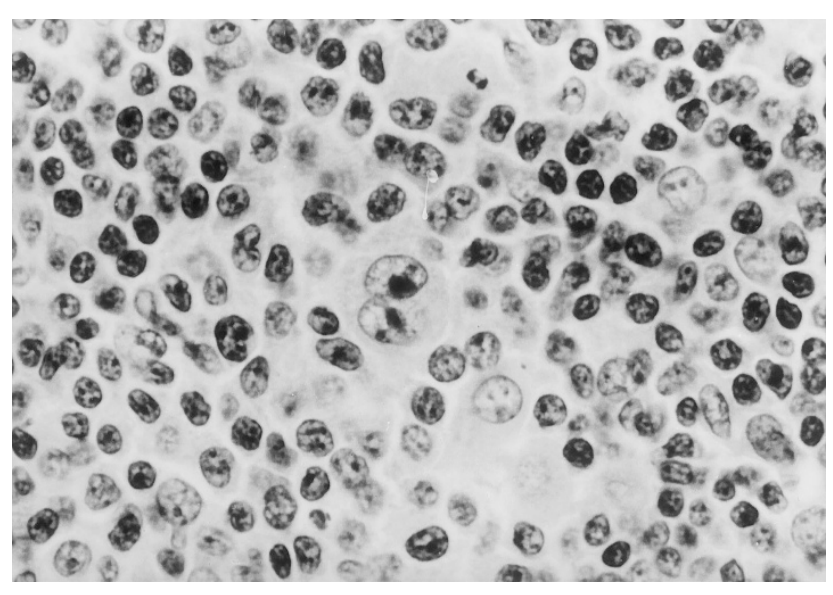

FIGURE 1. One of several classical binucleated Reed-Sternberg cells identified in the 1993 biopsy. 

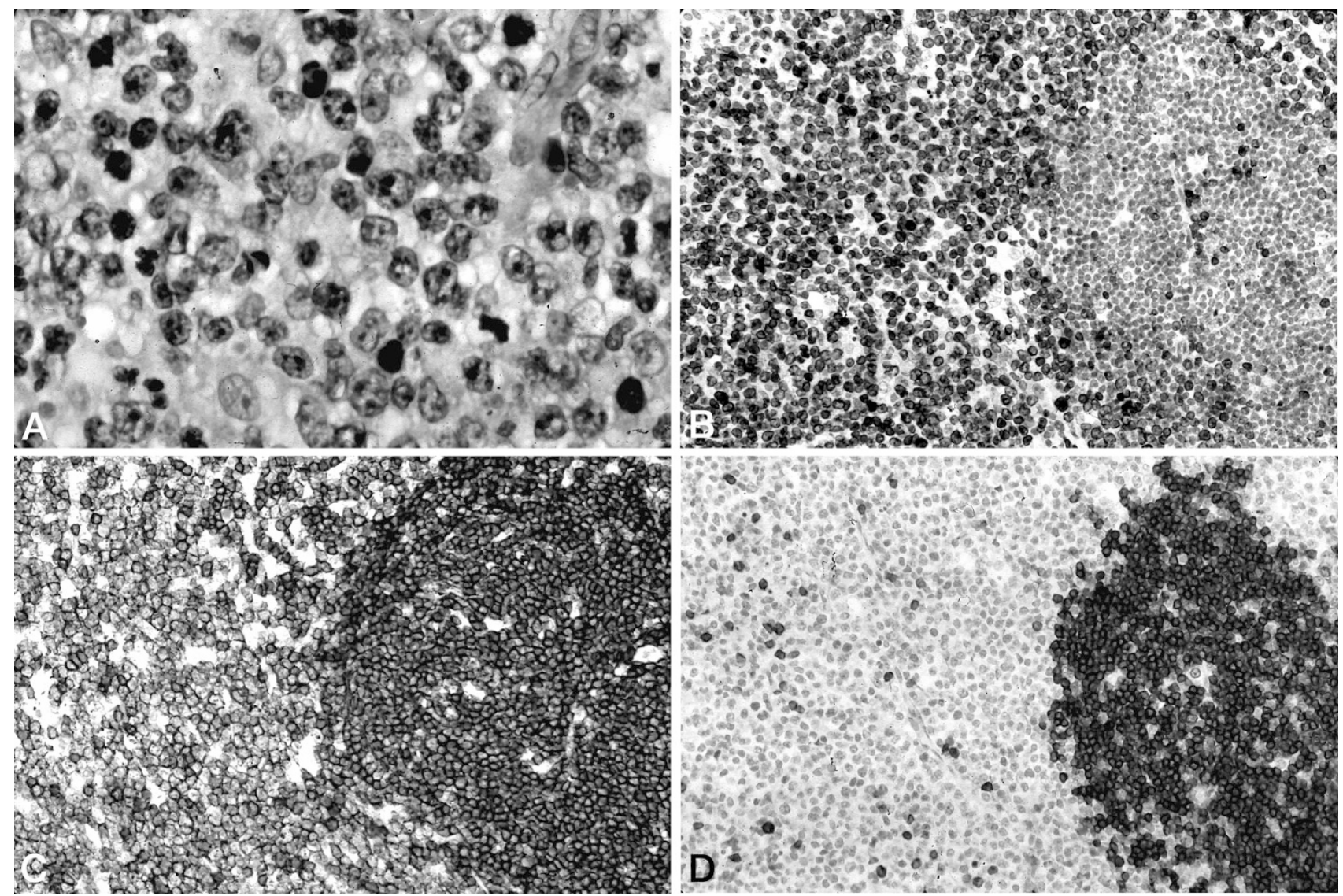

FIGURE 2. A, Hematoxylin and eosin appearance of the pleomorphic T-cell lymphoma identified in the 1998 biopsy. B, 1998 biopsy stained with CD3, highlighting the diffuse lymphoma, but not the reactive follicle. C, 1998 biopsy stained with CD20, showing strong staining of both the lymphoma and the reactive follicle. D, 1998 biopsy stained with CD79a, marking only the reactive follicle, and not the lymphoma.

abundant quantities of pale cytoplasm were admixed with occasional small lymphocytes, neutrophils, and apoptotic cells. There were numerous mitotic figures. Nuclei were predominantly vesicular, with one or more nucleoli. These cells had the following immunophenotype: CD2 positive, CD3 positive (Figure 2b), CD4 weakly positive, CD5 positive, CD8 negative, CD20 positive (Figure 2c), CD43 positive, CD45RB positive, CD45RO positive, CD30 focally positive, CD79a negative (Figure $2 \mathrm{~d}$ ), granzyme B negative, perforin negative, TIA-1 negative, EBV-LMP-1 negative. The lymphoma was EBV negative by in situ hybridization.

Additional results are shown as follows: immunohistochemical analysis in Table 1, flow cytometric analysis in Figures 3 and 4 and Table 2, and molecular diagnostic studies in Table 3 . The dot-plot histogram illustrated in Figure 3a shows the gated lymphocyte population identified with FSC (forward scatter, or size) versus SSC (side scatter, or granularity). The next histogram (Figure $3 b$ ) shows the gated population analyzed for CD5 and CD20. Two distinct populations are evident: one that is CD20 ${ }^{\text {bright }}, \mathrm{CD}^{\mathrm{dim}}$, and another that is $\mathrm{CD} 20^{\mathrm{dim} / \mathrm{neg}}$, $\mathrm{CD} 5{ }^{\text {bright }}$. The FSC versus SSC gate was divided into a smaller cell gate (R1) and a larger cell gate (R2)
TABLE 1. Immunohistochemical Phenotypes

\begin{tabular}{lll}
\hline \multicolumn{1}{c}{ Antigen } & \multicolumn{1}{c}{$\begin{array}{c}\text { Hodgkin's cells } \\
\text { (1993) }\end{array}$} & \multicolumn{1}{c}{$\begin{array}{c}\text { Lymphoma } \\
\text { (1998) }\end{array}$} \\
\hline CD45RB (LCA) & Negative & Positive \\
CD20 (L26) & Positive & Positive \\
CD45RA & Negative & Negative \\
CD79a & Weakly positive & Negative \\
CD2 & Negative & Positive \\
CD3 & Negative & Positive \\
CD4 & Negative & Scattered positive \\
& & cells \\
CD5 & Negative & Positive \\
CD8 & Negative & Negative \\
CD43 & Negative & Positive \\
CD45RO (UCHL-1) & Negative & Positive \\
CD15 (Leu-M1) & Rare cells weakly & Negative \\
& positive & Scattered positive \\
CD30 (Ber-H2) & Positive & cells \\
& & Negative \\
CD56 & Negative & Negative \\
Perforin & Weakly positive & Negative \\
Granzyme B & Negative & Negative \\
TIA-1 & Negative & Not performed \\
EMA & Negative & Negative \\
EBV-LMP-1 & Negative &
\end{tabular}

EMA, epithelial membrane antigen; EBV-LMP-1, Epstein-Barr virus latent membrane protein.

(Figure 4a) to test the hypothesis that these two populations might vary according to size. When the newly gated populations were then analyzed for 


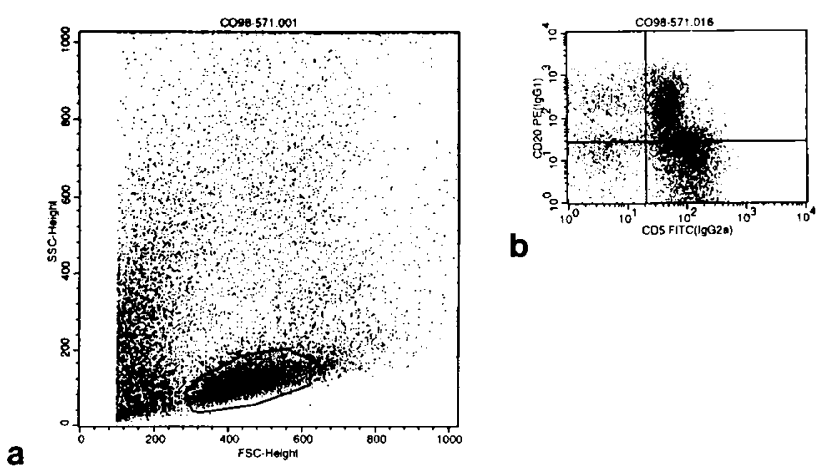

FIGURE 3. Flow cytometry dot plots of the 1998 case depicting (A) the lymphoid population gated on a forward scatter-side scatter plot and (B) the lymphoid population analyzed for CD5 and CD20.

CD20 and CD5 expression, one predominant CD20 and CD5 co-expressing population stood out in each instance: one was CD20 ${ }^{\mathrm{dim} / \text { neg }}, \mathrm{CD} 5^{\text {bright }}(\mathrm{R} 1$, smaller cells), and the other was CD20 ${ }^{\text {bright }}, \mathrm{CD}^{\mathrm{dim}}$ (R2, larger cells) (Figure 4b). Detection of CD2 and CD7 expression by both of these populations confirmed that both were composed of $\mathrm{T}$ cells (Figure 4c).

PCR analysis of paraffin-embedded tissue from the 1993 biopsy showed no evidence of TCR- $\gamma$ gene rearrangement, whereas PCR analysis of the 1998 biopsy showed a monoclonal rearrangement of the TCR- $\gamma$ chain gene $(V \gamma 9)$ (Figure 5). Southern blot analysis showed rearrangements of both the constant and joining regions of the TCR- $\beta$ gene in the EcoRI and HindIII digests (not shown). There was no evidence of immunoglobulin heavy-chain gene rearrangement detected by PCR analysis.

\section{DISCUSSION}

The CD20 antigen, a transmembrane protein that functions as a $\mathrm{Ca}^{2+}$-permeable cation channel (17, 18) has long been designated a "pan-B" antigen, present on a wide range of normal and neoplastic $B$ lymphocytes. Antibodies directed against CD20, such as L26 (Dako), are now routinely used for the paraffin section identification of B-cell lineage. CD20 appears on the surface of the pre-B lymphocyte between the time of light chain rearrangement and expression of intact surface immunoglobulin and is lost just before terminal B-cell differentiation into plasma cells. Surface expression of CD20 on activated B cells is approximately 4 -fold greater than that found on resting B cells, and CD20 function has been associated with cell cycle progression, which is $\mathrm{Ca}^{2+}$-dependent (19).

The gene for human CD20 is located on chromosome 11q12-q13, near the site of the $t(11 ; 14)$ (q13; 32) translocation, which occurs in a subpopulation of B cell malignancies, most notably mantle zone lymphoma, and was isolated and cloned in 1989
$(18,20)$. The transcriptional regulation of the gene is not yet completely understood, although several regulatory elements have been partially characterized. The $\mathrm{T}$ cell-derived lymphokine interleukin-4 (IL-4) seems to induce CD20 expression in the leukemic blasts of patients with acute lymphoblastic leukemia (ALL), but not in normal blood cell precursors from fetal bone marrow (21). Interleukin-7 has also been shown to induce CD20 expression in a Philadelphia-chromosome-positive ALL cell line and in a subset of fetal B-cell precursors $(22,23)$. In summary, CD20 seems to directly regulate transmembrane calcium conductance in B lymphocytes. This, in turn, regulates B-cell activation, proliferation, and differentiation (24).

CD20 has recently been reported on the surface of a small subset of normal and neoplastic T lymphocytes, usually with diminished intensity with respect to B lymphocytes when analyzed by flow cytometry-thus the appellation, "CD20 ${ }^{\mathrm{dim}} "(1,3$, 7-9). Quantitation of fluorescence intensity is directly related to the labeled antibody binding capacity and is an indirect measurement of surface antibody density. CD20 ${ }^{\text {dim }} \mathrm{T}$ lymphocytes represent as many as $12 \%$ of normal peripheral blood lymphocytes (7) and have a CD4:CD8 ratio of 0.6, compared with 1.8 among CD20-negative T cells (3). It has also been found that circulating CD20 ${ }^{\operatorname{dim}} \mathrm{T}$ lymphocytes increase with age and have a predominantly memory cytotoxic phenotype (CD8 positive, CD28 positive, CD45RO positive, TCR- $\alpha / \beta$ positive, CD38 negative, and human leukocyte antigen-DR negative) (25). In addition, they are more likely to be TCR- $\gamma / \delta$ positive and CD45RO positive than are CD20 negative T cells (3).

The functional role of CD20 in T lymphocytes has not been studied extensively; however, the surface expression of CD20 in monkey lymph node T cells increased when they were cultured with mitogen and interleukin-2 (26). Therefore, CD20 seems to be associated with an activated state and increased DNA synthesis in T cells as well as in B cells.

CD20-positive T-cell malignancies are rare, with only fifteen previously reported cases (Table 4). They have included pleomorphic medium- and large-cell lymphoma, immunoblastic lymphoma, anaplastic large cell lymphoma, convoluted lymphoblastic lymphoma, acute lymphoblastic leukemia, small lymphocytic lymphoma/chronic lymphocytic leukemia (CLL), and the current case of diffuse large cell lymphoma. Only two of the other reported cases have been shown to harbor TCR gene rearrangements $(5,8)$, although a third case showed loss of the germline TCR- $\beta$ band in the BamHI digest, implying early deletion of the rearranged TCR genes after malignant transformation (7). 


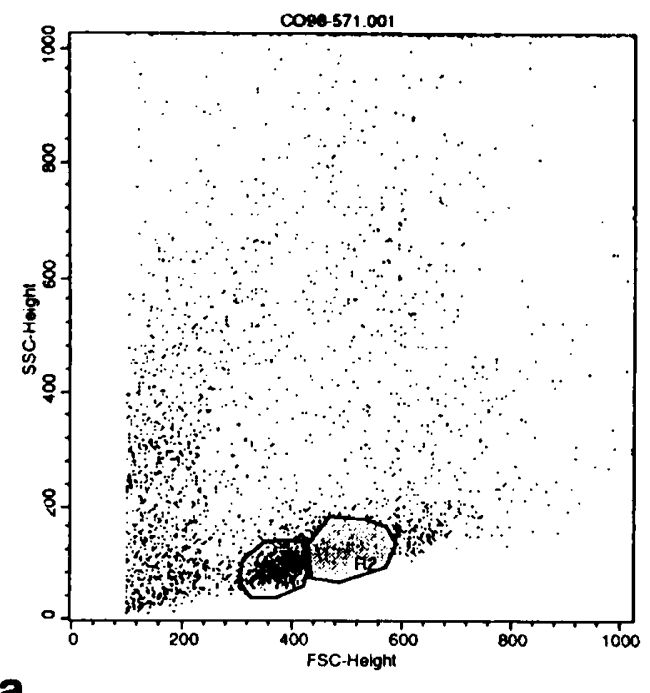

b
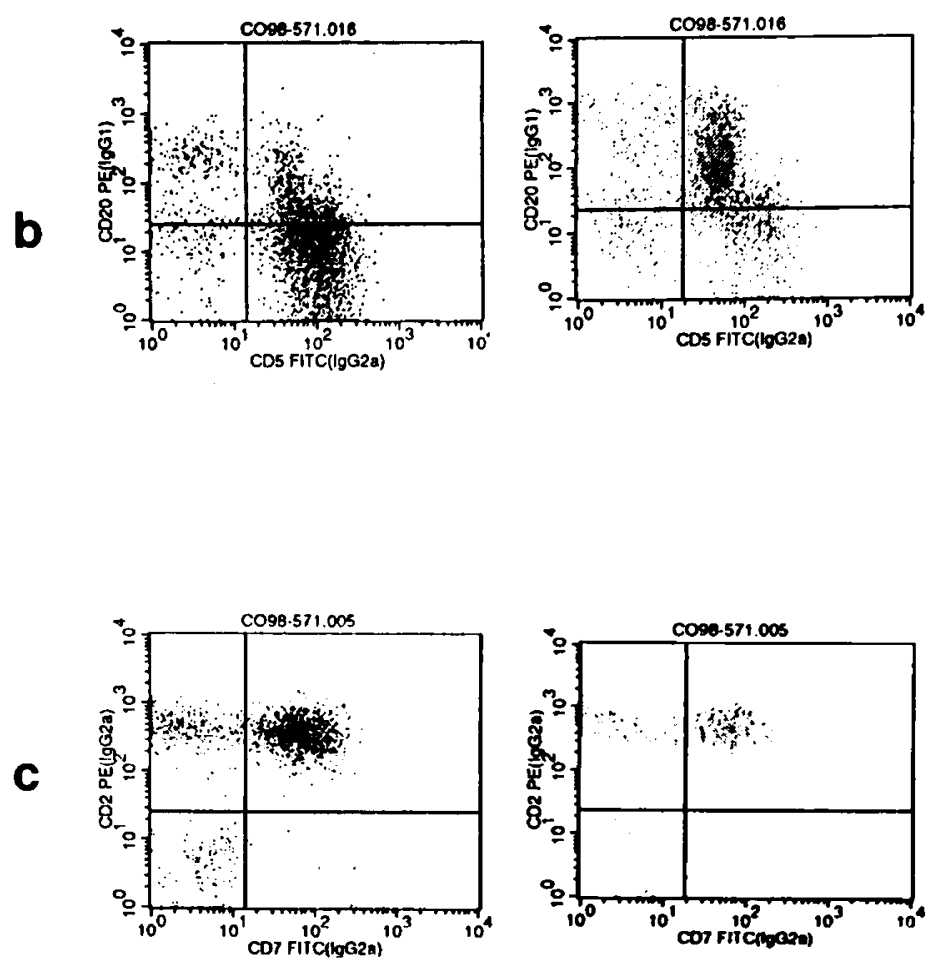

FIGURE 4. Flow cytometry dot plots of the 1998 case. A, the lymphoid population is divided into a smaller cell gate (R1) and a larger cell gate (R2). B, analysis for CD5 and CD20 (R1 shows a mixture of CD5 $5^{\text {bright }} / \mathrm{CD} 20^{\text {dim }}$ and CD20-negative cells while R2 shows a predominantly CD5 dim/CD20 ${ }^{\text {bright }}$ population). C, analysis for CD7 and CD2 (both R1 and R2 populations are positive for both CD7 and CD2).

TABLE 2. Flow Cytometry Data (1998)

\begin{tabular}{ll}
\hline Antibody & Result \\
\hline CD45 & Positive \\
CD14 & Negative \\
CD2 & Positive \\
CD4 & Positive \\
CD5 & Positive \\
CD7 & Positive \\
CD8 & Negative \\
CD10 & Negative \\
CD19 & Negative \\
CD20 & Positive \\
CD22 & Negative \\
CD23 & Negative \\
$\kappa$ & Negative \\
$\lambda$ & Negative \\
IgD & Negative \\
IgM & Negative \\
IgA & Negative \\
IgG & Positive \\
FMC7 & Negative \\
CD103 & Negative \\
\hline
\end{tabular}

${ }^{a}$ Two populations detected: one bright and one dim.

The case of chronic lymphocytic leukemia (TCLL) reported by Takami et al. (8) and the three cases of acute lymphoblastic leukemia reported by Warzynski et al. (9) are distinctive in that they describe clonal proliferations of $\mathrm{CD} 20^{\mathrm{dim}} \mathrm{T}$ cells (demonstrated by gene rearrangement and a combination of morphologic and immunophenotypic characteristics, respectively) that were analyzed by flow cytometry. The case of T-CLL expressed several activation antigens such as CD38 and human
TABLE 3. Molecular Diagnostic Studies

\begin{tabular}{lll}
\hline DNA/RNA locus (method) & \multicolumn{1}{c}{1993 biopsy } & \multicolumn{1}{c}{1998 biopsy } \\
\hline TCR- $\beta$ (Southern blot) & Not analyzed & Rearranged (C,J regions) \\
TCR- $\gamma$ (PCR) & Negative & Rearranged (V gamma 9) \\
Immunoglobulin JH (PCR) & Not analyzed & Negative \\
EBER-1 (ISH) & Negative & Negative \\
\hline
\end{tabular}

PCR, polymerase chain reaction; ISH, in situ hybridization; EBER, Epstein-Barr virus-encoded RNA.

leukocyte antigen-DR, suggesting that this neoplastic population had an "activated status," which is in keeping with the proposed role of CD20. These cases were not analyzed by immunohistochemistry, however. In the remaining cases, which were not analyzed by flow cytometry, it is not known whether the observed CD20 expression represented CD20 ${ }^{\text {dim }}$ or another form of CD20 expression; to our knowledge, the immunohistochemical staining pattern of CD20 dim cells has not been described (see below). Although the clonal expansion of reactive CD20-positive $\mathrm{T}$ cells seems to be the most likely mechanism for CD20 expressions in these neoplasms, re-expression of a fetal antigen, or merely the aberrant expression of CD20 after the neoplastic alteration, have not been ruled out $(1,7)$.

Two populations of CD20-positive $\mathrm{T}$ cells were seen in the current case, one bright and one dim (Figure $3 b$ ). Because the larger cells were morphologically malignant, we knew that the large-cell population (R2) was composed predominantly of 


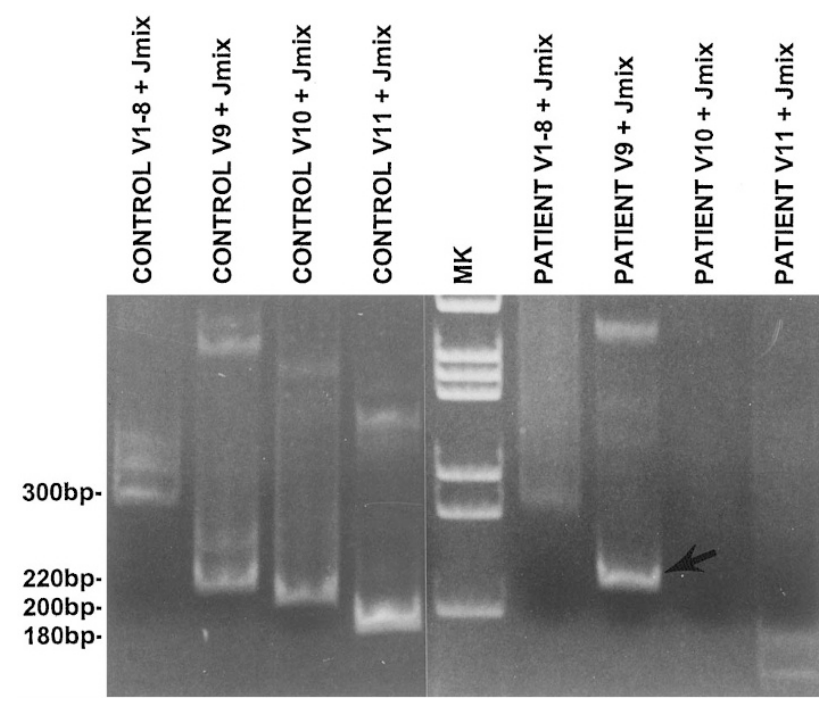

FIGURE 5. Polymerase chain reaction gel depicting a rearranged band for the T-cell receptor $\gamma(\mathrm{V} \gamma 9)$ gene (arrow) in the 1998 biopsy.

neoplastic CD20 $0^{\text {bright }} \mathrm{T}$ cells (which also showed dim expression of CD5) (Figure $4 \mathrm{~b}$ ). The small-cell population (R1) included a predominant population of CD20-negative (reactive) $\mathrm{T}$ cells admixed with either a subpopulation of smaller neoplastic CD20 ${ }^{\operatorname{dim}} \mathrm{T}$ cells, a population of small reactive CD20 ${ }^{\text {dim }} \mathrm{T}$ cells (from which the neoplasm may have developed), or a combination of the two.

The existence of CD20 bright and CD20 dim populations may reflect modifications of the CD20 molecule (for instance, different degrees of CD20 phosphorylation in the two populations). In B cells, CD20 becomes phosphorylated upon mitogen activation, and phosphorylation is thought to be one molecular regulatory mechanism of CD20 function (27). Varying degrees of phosphorylation result in different cell surface isoforms of the antigen, which may show differential binding capacities with any given monoclonal CD20 antibody (and differential "brightness" or intensity when analyzed by flow cytometry). Monoclonal antibody binding to CD20 generates a transmembrane signal that results in enhanced phosphorylation of the molecule and inhibits B-lymphocyte differentiation and activation (20). A molecular mechanism such as increased phosphorylation may thus decrease binding capacity and account for the resting memory B- or T-cell/ precursor CD20 ${ }^{\mathrm{dim}}$ phenotype. Further studies targeting the nature of CD20 molecular regulatory mechanisms may elucidate the reason for CD20 ${ }^{\text {bright }}$ and CD20 ${ }^{\text {dim }}$ expression.

In the study by Moreau et al. cited above (23), cultured $\mathrm{CD} 20^{\mathrm{dim}}$ fetal B-cell precursors maintained maturational potential to become $\mathrm{CD} 20^{\text {bright }}$ cells. In addition, CD20 dim cells were shown to proliferate at a level considerably higher than CD20 ${ }^{\text {bright }}$ cells. In addition, CD20 ${ }^{\mathrm{dim}}$ cells were shown to proliferate at a considerably higher level than $\mathrm{CD} 20^{\text {bright }}$ cells. In another study, decreased fluorescence intensity of CD20 reagents on B cell chronic lymphocytic leukemia lymphocytes compared with normal peripheral blood B lymphocytes was noted and subsequently confirmed by titration studies (28). This provides further support for the hypothesis that CD20 ${ }^{\mathrm{dim}}$ neoplasms may represent tumors of small memory B- or T cells/precursors which have been induced to proliferate at a high rate in response to a mitogen or to an antigen to which they have been previously exposed. Additionally, in the current case, the possible presence of both $\mathrm{CD} 20^{\text {bright }}$ and CD20 ${ }^{\text {dim }}$ components of the neoplasm suggests that a subpopulation of CD20 dim $\mathrm{T}$ lymphocytes, when clonally expanded, aberrantly has the capacity to "mature" (in B-cell fashion) into CD20 bright cells.

As pointed out by Warzynski et al., paraffin section immunohistochemistry using L26 may not provide the level of sensitivity required for identification of CD20 dim expression (9). Thus, these neoplasms might only be able to be identified by flow cytometry, unless, as in our case, there is a significant proportion of $\mathrm{CD} 20^{\text {bright }}$ cells, as well. Algino et al. emphasized that using the combination of CD5 and CD20 to analyze atypical lymphoid populations may result in confusion of CD5-expressing B cells and CD20-expressing T cells (1). Therefore, the combination of CD5 and CD19 is recommended for the identification of CLL/ SLL or mantle cell lymphoma and the combination of CD3 and CD20 for the identification of CD20expressing T-cell malignancies.

The detection of rare cases such as the current one also suggests that the use of only CD20, CD5, and CD43 antibodies in paraffin section immunohistochemistry may lead to inappropriate lineage designation $(1,7)$. Co-expression of CD20 and CD43 (or CD5) commonly occurs in low grade B-cell lymphomas and may be diagnostically useful in distinguishing low grade B-cell lymphoma from reactive $\mathrm{B}$-cell proliferations. The addition of a third B- or T-lineage marker (such as CD79a or CD3) is necessary to further confirm or exclude B- or T-lineage.

The appearance of non-Hodgkin's lymphoma subsequent to treatment of Hodgkin's disease has been described in approximately $5 \%$ of cases (29). The risk of secondary non-Hodgkin's lymphoma is greater in patients showing evidence of underlying immunodeficiency or immune suppression, such as low peripheral blood lymphocyte counts, advanced clinical stage, or systemic symptoms. The lymphoma is generally of B-cell lineage, and is usually high-grade; however, in up to $44 \%$ of reported cases, the lymphoma is of T-cell lineage (30). In one report, only $14 \%$ of B-cell non-Hodgkin's lymphoma that followed Hodgkin's disease contained EBV when studied by in situ hybridization for EBER-1 mRNA. These secondary lymphomas often 


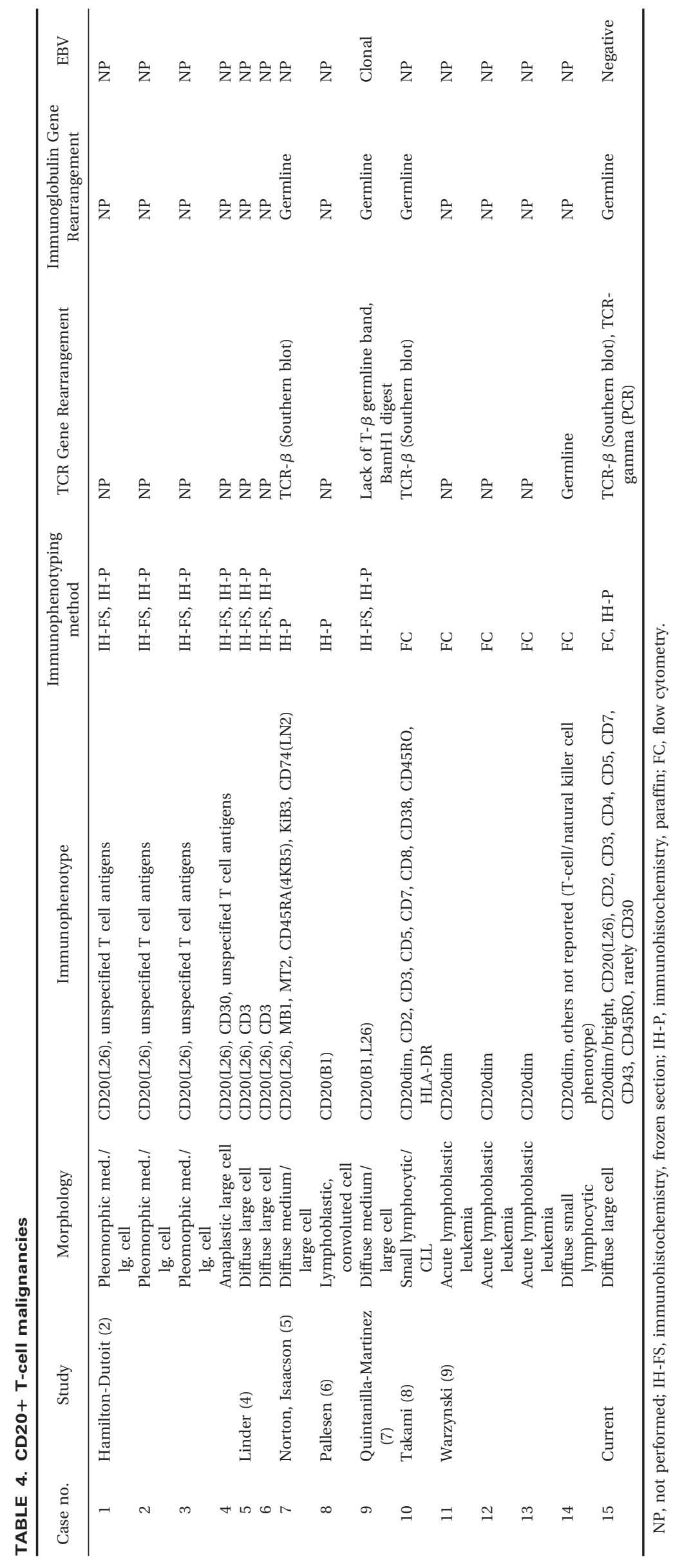


follow an aggressive clinical course with advanced stages and extranodal involvement, and the time interval between the diagnoses is reportedly 1 year or less in one third of the cases. These data do not correlate with the course of the patient in our case thus far; however, whether the expression of CD20 in secondary $\mathrm{T}$-cell neoplasms will prove to have any prognostic value is unknown.

Underlying defects in cell-mediated immunity are known to be present among patients with Hodgkin's disease $(31,32)$ and, as noted above, these patients are also at increased risk for secondary cancers (33). Although a clonal relationship between Hodgkin's disease and a subsequent lymphoma is suggested in some cases (29), the two diseases in our patient most likely represent separate clonal processes. Although no TCR rearrangement was detected in the Hodgkin's disease tissue (immunoglobulin gene rearrangement was not sought), microdissection of Reed-Sternberg cells was not performed, so it is possible that the sample selected for analysis was too poor in ReedSternberg cells to allow detection of gene rearrangement. To date, there have been many reports of immunoglobulin heavy-chain gene rearrangement in Reed-Sternberg cells (34). In addition, there have been two recent reports of TCR gene rearrangement $(35,36)$. Our case of Hodgkin's disease shared perforin expression with some of the T-lineage cases; however, the subsequent T-cell lymphoma in our patient did not express any cytotoxic markers.

In our patient, there was no recognized immunodeficiency before the development of Hodgkin's disease, so the non-Hodgkin's lymphoma may have been primarily chemotherapy-related, caused by the immunodeficiency of Hodgkin's disease itself, or merely coincidental. The patient's long smoking history, as well as a family history of diabetes and cancer in a sister at a young age, however, suggest that there may indeed have been an underlying immunologically dysfunctional state. Lack of evidence for EBV in both the Reed-Sternberg cells and the T-cell lymphoma implies that EBV infection did not play a role in the pathogenesis of these lesions.

\section{REFERENCES}

1. Algino KM, Thomason RW, King DE, Montiel MM, Craig FE. CD20 (pan-B cell antigen) expression on bone marrowderived T cells. Am J Clin Pathol 1996;106:78-81.

2. Hamilton-Dutoit SJ, Pallesen G. B cell associated monoclonal antibody L26 may occasionally label T cell lymphomas. APMIS 1989;97:1033-6.

3. Hultin LE, Hausner MA, Hultin PM, Giorgi JV. CD20 (pan-B cell) antigen is expressed at a low level on a subpopulation of human T lymphocytes. Cytometry 1993;14:196-204.

4. Linder J, Ye Y, Armitage JO, Weisenburger DD. Monoclonal antibodies marking B-cell non-Hodgkin's lymphoma in paraffin-embedded tissues. Mod Pathol 1988;1:29-34.

5. Norton AJ, Isaacson PG. Monoclonal antibody L26: An antibody that is reactive with normal and neoplastic B lympho- cytes in routinely fixed and paraffin wax embedded tissues. J Clin Pathol 1987;40:1405-12.

6. Pallesen G. Immunohistological analysis of tissue specificity of the 52 workshop anti-B lymphocyte monoclonal antibodies. Cancer Rev 1988;8:277-88.

7. Quintanilla-Martinez L, Preffer F, Rubin D, Ferry JA, Harris NL. CD20 + T cell lymphoma: Neoplastic transformation of a normal T-cell subset. Am J Clin Pathol 1994;102:483-9.

8. Takami A, Saito M, Nakao S, Asakura H, Nozue T, Onoe Y, et al. CD20-positive T-cell chronic lymphocytic leukaemia. $\mathrm{Br}$ J Haematol 1998;102:1327-9.

9. Warzynski JJ, Graham DM, Axtell RA, Zakem MH, Rotman RK. Low level CD20 expression on T cell malignancies. Cytometry 1994;18:88-92.

10. Battifora H, Alsabeh R, Jenkins KA, et al. Epitope retrieval (unmasking) in immunohistochemistry. Adv Pathol Lab Med 1995;8:101-18.

11. Sheibani K, Tubbs RR. Enzyme immunohistochemistry: Technical aspects. Semin Diagn Pathol 1984;1:235-50.

12. Borowitz MJ, Guenther KL, Shults KE, Stelzer GT. Immunophenotyping of acute leukemia by flow cytometric analysis: use of CD45 and right-angle light scatter to gate on leukemic blasts in three-color analysis. Am J Clin Pathol 1993;100:534-40.

13. Chang KL, Chen Y, Shibata D, Weiss LM. Description of an in situ hybridization methodology for detection of Epstein-Barr virus RNA in paraffin-embedded tissues, with a survey of normal and neoplastic tissues. Diagn Mol Pathol 1992;1: 246-55.

14. Ben-Ezra J. Variable rate of detection of immunoglobulin heavy chain V-D-J rearrangement by PCR: a systematic study of 41 B-cell non-Hodgkin's lymphomas and leukemias. Leuk Lymphoma 1992;7:289-95.

15. Segal GH, Jorgensen T, Masih AS, Braylan RC. Optimal primer selection for clonality assessment by polymerase chain reaction analysis: I. Low grade B-cell lymphoproliferative disorders of nonfollicular center cell type. Hum Pathol 1994;25:1269-75.

16. Greiner TC, Raffeld M, Lutz C, Dick F, Jaffe ES. Analysis of T cell receptor-gamma gene rearrangements by denaturing gradient gel electrophoresis of GC-clamped polymerase chain reaction products. Correlation with tumor-specific sequences. Am J Pathol 1995;146:46-55.

17. Bubien JK, Zhou LJ, Bell PD, Frizzell RA, Tedder TF. Transfection of the CD20 cell surface molecule into ectopic cell types generates a $\mathrm{Ca}^{2+}$ conductance found constitutively in B lymphocytes. J Cell Biol 1993;121:1121-32.

18. Chang KL, Arber DA, Weiss LM. CD20: A review. Appl Immunohistochem 1996;4:1-15.

19. Kanzaki M, Shibata H, Mogami H, Kojima I. Expression of calcium-permeable cation channel CD20 accelerates progression through the G1 phase in Balb/c 3T3 cells. J Biol Chem 1995;270:13099-104.

20. Tedder TF, Klejman F, Schlossman SF, Saito H. Structure of the gene encoding the human B lymphocyte differentiation antigen CD20(B1). J Immunol 1989;142:2560-8.

21. Pandrau D, Saeland S, Duvert V, Durand I, Manel AM, Zabot MT, et al. Interleukin 4 inhibits in vitro proliferation of leukemic and normal human B cell precursors. J Clin Invest 1992;90:1697-706.

22. Ohyashiki K, Miyauchi J, Ohyashiki JH, Saito M, Yaguchi M, Inatomi $\mathrm{Y}$, et al. Interleukin-7 enhances colony growth and induces $\mathrm{CD} 20$ antigen of a $\mathrm{Ph}+$ acute lymphoblastic leukemia cell line, OM9;22. Leukemia 1993;81:1034-40.

23. Moreau I, Duvert V, Banchereau J, Saeland S, et al. Culture of human fetal blood B-cell precursors on bone marrow stroma maintains highly proliferative CD20 dim cells . Blood 1993;1170-8.

24. Clark EA, Shu G, Ledbetter JA. Role of the Bp35 cell surface polypeptide in human B cell activation. Proc Natl Acad Sci U S A 1985;82:1766-70. 
25. Storie I, Wilson GA, Granger V, Barnett D, Reilly JT. Circulating CD20dim $\mathrm{T}$ lymphocytes increase with age: evidence for a memory cytotoxic phenotype. Clin Lab Haematol 1995; $17: 323-8$

26. Murayama Y, Mukai R, Sata T, Matsunaga S, Noguchi A, Yoshikawa Y. Transient expression of CD20 antigen (pan B cell marker) in activated lymph node T cells. Microbiol Immunol 1996;40:467-71.

27. Zhou LJ, Tedder, TF. CD20 Workshop Panel report. In: Schlossman SF, et al., editors. Leukocyte typing: white cell differentiation Antigens, 5. Oxford, U.K.: Oxford University Press; 1995. p. 511-4.

28. Marti GE, Vogt, R, Zenger, P, Abassi, F, Washington, GC, Hontanon, RJ, et al. The binding capacity of CD20 reagents. In: Schlossman SF, et al., editors. Leukocyte typing: white cell differentiation antigens, 5. Oxford, U.K.: Oxford University Press; 1995. p. 515-5.

29. Jaffe ES, Zarate-Osorno A, Medeiros LJ. The interrelationship of Hodgkin's disease and non-Hodgkin's lymphomas-lessons learned from composite and sequential malignancies. Semin Diagn Pathol 1992;9:297-303.

30. Amini RM, Enblad G, Sundstrom C, Glimelius B. Patients suffering from both Hodgkin's disease and non-Hodgkin's lymphoma: A clinico-pathological and immuno- histochemical population-based study of 32 patients. Int J Cancer 1997;71:510-6.

31. Levy R, Kaplan HS. Impaired lymphocyte function in untreated Hodgkin's disease. N Engl J Med 1974;290:181-6.

32. Fisher RI, DeVita VT Jr, Bostick F, Vanhaelen C, Howser DM, Hubbard SM, et al. Persistent immunologic abnormalities in long-term survivors of advanced Hodgkin's disease. Ann Intern Med 1980;92:595-9.

33. Henry-Amar M. Second cancer after treatment for Hodgkin's disease: a report from the international database on Hodgkin's disease. Ann Oncol 1992;3:117-28.

34. Stein H, Diehl V, Marafioti T, Jox A, Wolf J, Hummel M. The nature of Reed-Sternberg cells, lymphocytic and histiocytic cells and their molecular biology in Hodgkin's disease. In: Mauch PM, Armitage JO, Diehl V, Hoppe RT, Weiss LM, editors. Hodgkin's disease. Philadelphia: Lippincott Williams \& Wilkins; 1998. p. 121-37.

35. Muschen M, Rajewsky K, Brauninger A, Baur AS, Oudejans JJ, Roers A, et al. Rare occurrence of classical Hodgkin's disease as a T cell lymphoma. J Exp Med 2000;191:387-94.

36. Seitz V, Hummel M, Marafioti T, Anagnostopoulos I, Assaf C, Stein H. Detection of clonal T-cell receptor gamma-chain gene rearrangements in Reed-Sternberg cells of classic Hodgkin disease. Blood 2000;95:3020-4.

\section{THE ARTHUR PURDY STOUT ANNUAL PRIZE}

The Arthur Purdy Stout Society of Surgical Pathologists is soliciting nominations for the 2001 Arthur Purdy Stout Prize to be awarded at the 2001 Spring USCAP Meeting. The prize in the amount of $\$ 2,000$ is awarded annually to a surgical pathologist under the age of 45 . The Prize is intended to recognize significant career achievements in Surgical Pathology by young surgical pathologists whose research publications, whether clinical or basic, have had a major impact on diagnostic pathology. Documentation should include three to four publications selected by the applicants or nominator as their most significant contributions as well as a curriculum vitae and a summary of the candidate's achievements in Surgical Pathology. Nominations should be made by a member of the Arthur Purdy Stout Society and should be forwarded with five copes to the Chairman of the Arthur Purdy Stout Awards Committee:

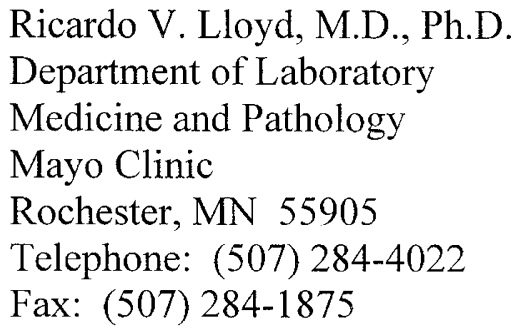

Nominations should be received by January 19, 2001 . 